\title{
Dynamic pressure evaluation near submerged breakwaters
}

\author{
F. T. Pinto \& A. C. V. Neves \\ Hydraulics and Water Resources Institute, Faculty of Engineering, \\ University of Porto, Portugal
}

\begin{abstract}
The increasing use of submerged breakwaters is not only due to their important role in beach protection, but also because of their low environmental impact. In their design process, an analysis of the pressure fields (near and along the structure slope) under wave flow is needed. Although a considerable amount of research has been conducted in order to improve our understanding of these structures behaviour and establish reliable formulae for design purposes, several outstanding questions remain.

This paper aims to present the evolution of dynamic pressure fields when the structure is submitted to the action of regular incident waves. These pressure fields are obtained by indirect means, through the measured horizontal wave flow velocity component as a function of the wave phase and water depth.

Keywords: submerged breakwater, wave-induced pressure fields, dynamic pressure.
\end{abstract}

\section{Introduction}

Submerged breakwaters are used for coastal and harbour structure protection. They are usually detached and parallel to the shoreline, with their crest heights fixed below a specified design water level to allow for the passage of some wave energy. Since they are less vulnerable to wave action and have a lower crest height, the required volume of material is less than for emerged breakwaters. A number of authors prefer submerged breakwaters for coastal protection since, in addition to defending the coastline from erosion, they (if well designed) do not disturb the landscape scenery and thus contribute to the preservation of the environment, which is one of the major design priorities at the moment. This 
type of structure also acts as an active primary defence during extreme wave climates by providing some wave energy dissipation. On the other hand, they require a more sophisticated design/project and, often, an adequate buoy/marker system to mark navigation hazards, since their crest height is near the surface (Lamberti \& Mancinelli [12]).

The main purpose of submerged breakwater is to provide a "filtered" shelter for the coast on their lee-side by dissipating the highest incoming waves. Like other coastal structures, they are submitted to different kinds of wave actions which can be predicted by wave theory analysis. These actions frequently cause damage to maritime structures and can affect the overall strength and reliability of blocks structures. The role of wave-induced pressure diagrams has great importance in breakwater design, to calculate the forces acting on the structure.

In this paper a summary review of the literature will be presented, followed by an overview of the assumptions and analysis techniques used in the current study. A description of the experimental set-up and a discussion of the results will also be presented. The evolution of dynamic pressure caused by regular incident wave actions in the vicinity of submerged structure slopes, as a function of the wave phase and water depth, will also be analysed. These results were obtained indirectly, using laboratory measurements of horizontal wave velocities taken in previous research projects.

\section{Wave-induced pressure fields}

\subsection{Introduction}

Submerged breakwaters have been the subject of numerous studies and investigations. Many authors have studied the performance of submerged breakwaters in coastal protection and pointed out advantages such as their reduced visual and environmental impact and other benefits in comparison to more traditional structures. The importance of a careful design (considering the transmission coefficient, crest submergence, crest height and width, sufficient distance from the shoreline, etc.) has also been discussed.

Some numerical approaches trying to simulate a wave field near, over and after passing a submerged structure have also been carried out, as in Chen \& Chen [5], Lara [13] and others.

Taveira-Pinto et al. ([18], [19]), Hsu et al. [11], Gironella \& Sánchez-Arcilla [9], Browder et al. [2] and Groenewoud et al. [10] have conducted experimental studies to better understand the physical effects of submerged breakwaters on the surrounding area. Most of them are concerned with the importance of wavestructure interaction processes (e.g. wave transmission, reflection and dissipation), the crest height and width, the ratio between the freeboard and the wave length, sediment transport, turbulence, the gaps and the consequences of scour, among other factors.

Since the processes and variables involved in the design of submerged breakwaters are less understood and rather more complex than in emerged breakwaters there is still a lot of research to be done, although in recent years 
there have been some studies which provide valuable information on the most important forces and processes to be considered. One of those forces is due to the wave motion, acting mostly as pressure forces (impacts) and as shear forces, on the structure slope. On impermeable and smooth breakwater slopes, percolation effects are not important, and forces depend only on the energy transformation process (Taveira-Pinto et al. [18]).

Determining the pressure fields caused by the wave action on a coastal structure is essential to good design, by allowing the calculation of the resultant forces. Several researchers have investigated methods of establishing these wave-induced forces, including Fuhrboter [8], Burchart [4], Allsop et al. [1], Martin et al. [15], Bullock et al. [3], Luís [14] and Taveira-Pinto \& Neves [21]. These authors studied: (a) the wave loading on vertical, composite and perforated caisson breakwaters; (b) the effects of wave obliquity and multidirectionality on the response of the breakwaters; (c) the design methods for wave loading; (d) the scale effects and (e) compared the results from field measurements with those measured in the laboratory and predicted by theories.

An accurate estimate of wave-induced dynamic pressures is essential, therefore, as it allows calculation of the wave forces and moments acting on a structure slope.

\subsection{Dynamic pressure evaluation}

The wave flow interference with a submerged breakwater generates a standing or partially standing wave field (caused by the reflection of the incident wave). A part of the incident energy is transmitted and the remaining part is absorbed by the structure (Taveira Pinto [19]).

The linear theory (Demirbilek \& Vincent [7] provides a good first estimate of wave parameters. Waves are considered as two-dimensional and of small amplitude, and the nonlinear terms in the boundary conditions are ignored. This is only possible when velocities are small, e.g., when waves have small amplitudes.

The pressure field, $p$, associated with a partially standing wave is determined from the unsteady Bernoulli equation, developed for non-rotational flows and expressed by

$$
\frac{\mathrm{p}}{\rho}+\mathrm{gz}+\frac{1}{2}\left(\mathrm{u}^{2}+\mathrm{v}^{2}\right)-\frac{\partial \phi}{\partial \mathrm{t}}=\mathrm{C}(\mathrm{t})
$$

where $\mathrm{p}$ represents the pressure in a point at the depth $-\mathrm{z}, \rho$ the fluid mass density, $g$ the gravitational acceleration, $\mathrm{u}$ and $\mathrm{v}$ the horizontal and vertical components of velocity, respectively, and $\phi$ the velocity potential.

Dean \& Dalrymple [6] reduced the previous equation to

$$
\frac{\mathrm{p}}{\rho}=-\mathrm{gz}+\frac{\partial \phi}{\partial \mathrm{t}}
$$

by neglecting the small velocity square terms, for a point at depth $-\mathrm{z}$.

A partial standing wave is produced by the interaction of two progressive waves moving in opposite directions, with wave heights equal to half of the 
standing wave height and having the same period. Thus, the velocity potential for partially standing waves is given by the subtraction of the velocity potential of two progressive waves,

$$
\begin{aligned}
& \phi=-\frac{\mathrm{H}_{\mathrm{i}}}{2} \frac{\mathrm{g}}{\sigma} \frac{\cosh [\mathrm{k}(\mathrm{z}+\mathrm{d})]}{\cosh (\mathrm{kd})} \operatorname{sen}(\mathrm{kx}-\sigma \mathrm{t})+\frac{\mathrm{H}_{\mathrm{r}}}{2} \frac{\mathrm{g}}{\sigma} \frac{\cosh [\mathrm{k}(\mathrm{z}+\mathrm{d})]}{\cosh (\mathrm{kd})} \operatorname{sen}(\mathrm{kx}+\sigma \mathrm{t}+\varepsilon) \\
& =\frac{\mathrm{g}}{2 \sigma} \frac{\cosh [\mathrm{k}(\mathrm{z}+\mathrm{d})]}{\cosh (\mathrm{kd})}\left[-\mathrm{H}_{\mathrm{i}} \operatorname{sen}(\mathrm{kx}-\sigma \mathrm{t})+\mathrm{H}_{\mathrm{r}} \operatorname{sen}(\mathrm{kx}+\sigma \mathrm{t}+\varepsilon)\right]
\end{aligned}
$$

where $\mathrm{H}_{\mathrm{i}}$ and $\mathrm{H}_{\mathrm{r}}$ represent the incident and the reflected wave heights respectively, $\mathrm{k}$ is the wave number (equal to $2 \pi / \mathrm{L}$ ), $\mathrm{L}$ is the wavelength, $\sigma$ is the angular frequency (equal to $2 \pi / T$ ), $T$ is the wave period, $d$ is the water depth and $\varepsilon$ is the wave phase delay, induced by the reflection process (equal to zero in the case of theoretical total reflection).

The height of the reflected wave can be calculated by

$$
\mathrm{H}_{\mathrm{r}}=\mathrm{C}_{\mathrm{r}} \mathrm{H}_{\mathrm{i}}
$$

where $\mathrm{C}_{\mathrm{r}}$ represents the reflection coefficient.

Rearranging equation (2), one can obtain

$$
\begin{aligned}
\mathrm{p} & =-\rho \mathrm{gz}+\rho \frac{\partial \phi}{\partial \mathrm{t}} \\
& =\underbrace{-\rho \mathrm{gz}}_{\substack{\text { hydrostatic } \\
\text { pressure, } \mathrm{ph}^{-}}}+\underbrace{\rho \mathrm{H}_{\mathrm{i}} \frac{\mathrm{g}}{2} \frac{\cosh [\mathrm{k}(\mathrm{z}+\mathrm{d})]}{\cosh (\mathrm{kd})}\left[\cos (\mathrm{kx}-\sigma \mathrm{t})+\mathrm{C}_{\mathrm{r}} \cos (\mathrm{kx}+\sigma \mathrm{t}+\varepsilon)\right]}_{\begin{array}{c}
\text { dynamic } \\
\text { pressure, } \mathrm{p}_{\mathrm{d}}
\end{array}}
\end{aligned}
$$

Looking at equation (5) one can say that the resulting pressure, p, will be the contribution of two effects: the hydrostatic pressure and the dynamic pressure due to acceleration and directly related with the water elevation.

\section{Indirect analysis of dynamic pressure}

\subsection{Introduction}

The main objective of this work was to assess dynamic pressure profiles, $\mathrm{p}_{\mathrm{d}}$, acting on a submerged breakwater. Experimental data from the measurements undertaken in the Hydraulics Laboratory of the Faculty of Engineering of Porto and a theoretical approach were used to calculate dynamic pressure from the horizontal component of the velocity at different points along the slopes, measured during previous projects. Two structures were tested (one rough and one smooth) and horizontal velocity measurements were obtained for regular incident waves.

\subsection{Dynamic pressure and the horizontal velocity component}

Isolating the term corresponding to the dynamic pressure, $\mathrm{p}_{\mathrm{d}}$, from equation (5), gives

$$
\mathrm{p}_{\mathrm{d}}=\rho \mathrm{H}_{\mathrm{i}} \frac{\mathrm{g}}{2} \frac{\cosh [\mathrm{k}(\mathrm{z}+\mathrm{d})]}{\cosh (\mathrm{kd})}\left[\cos (\mathrm{kx}-\sigma \mathrm{t})+\mathrm{C}_{\mathrm{r}} \cos (\mathrm{kx}+\sigma \mathrm{t}+\varepsilon)\right]
$$


According to linear wave theory, the horizontal component of velocity is expressed by

$$
\begin{aligned}
& \mathrm{u}=-\frac{\partial \phi}{\partial \mathrm{x}}=\frac{\mathrm{g}}{2 \sigma} \frac{\cosh [\mathrm{k}(\mathrm{z}+\mathrm{d})]}{\cosh (\mathrm{kd})}\left[-\mathrm{kH}_{\mathrm{i}} \cos (\mathrm{kx}-\sigma \mathrm{t})+\mathrm{k}_{\mathrm{r}} \cos (\mathrm{kx}+\sigma \mathrm{t}+\varepsilon)\right] \\
& =-\mathrm{H}_{\mathrm{i}} \frac{\mathrm{g}}{2 \sigma} \frac{\cosh [\mathrm{k}(\mathrm{z}+\mathrm{d})]}{\cosh (\mathrm{kd})}(-\mathrm{k})\left[\cos (\mathrm{kx}-\sigma \mathrm{t})-\mathrm{C}_{\mathrm{r}} \cos (\mathrm{kx}+\sigma \mathrm{t}+\varepsilon)\right] \\
& =\mathrm{H}_{\mathrm{i}} \frac{\mathrm{k}}{\sigma} \frac{\mathrm{g}}{2} \frac{\cosh [\mathrm{k}(\mathrm{z}+\mathrm{d})]}{\cosh (\mathrm{kd})}\left[\cos (\mathrm{kx}-\sigma \mathrm{t})-\mathrm{C}_{\mathrm{r}} \cos (\mathrm{kx}+\sigma \mathrm{t}+\varepsilon)\right]
\end{aligned}
$$

Equation (6) can be re-typed as follows:

$$
\begin{aligned}
& \frac{p_{d}}{u}=\frac{\rho H_{i} \frac{g}{2} \frac{\cosh [k(z+d)]}{\cosh (k d)}\left[\cos (k x-\sigma t)+C_{r} \cos (k x+\sigma t+\varepsilon)\right]}{H_{i} \frac{k}{\sigma} \frac{g}{2} \frac{\cosh [k(z+d)]}{\cosh (k d)}\left[\cos (k x-\sigma t)-C_{r} \cos (k x+\sigma t+\varepsilon)\right]} \\
& =\rho \frac{\sigma}{k} \frac{\cos (k x-\sigma t)+C_{r} \cos (k x+\sigma t+\varepsilon)}{\cos (k x-\sigma t)-C_{r} \cos (k x+\sigma t+\varepsilon)}
\end{aligned}
$$

which is equal to

$$
p_{d}=\rho u C \frac{\cos (k x-\sigma t)+C_{r} \cos (k x+\sigma t+\varepsilon)}{\cos (k x-\sigma t)-C_{r} \cos (k x+\sigma t+\varepsilon)}
$$

where $\mathrm{C}$ represents the wave celerity, equal to $\mathrm{L} / \mathrm{T}$, assuming that it remains constant in the vicinity of the structure.

Hence, it can be concluded that by knowing the values of $\rho, \mathrm{C}, \mathrm{u}, \mathrm{Cr}$ and $\varepsilon$, one can estimate the dynamic pressure, $\mathrm{p}_{\mathrm{d}}$, at different $x$ positions.

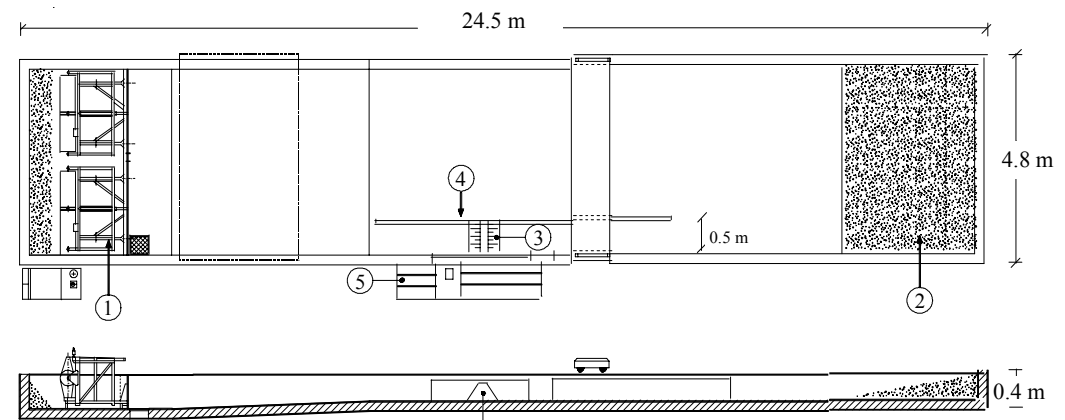

(3)

Figure 1: $\quad$ Layout of the FEUP Hydraulics Laboratory (1-Wavemaker; 2Dissipating beach; 3-Model; 4-Thin dividing wall; 5-Traversing table).

\section{Experimental set-up}

Velocity measurements were carried out in a unidirectional wave tank at the Porto University Faculty of Engineering, schematised in Figure 1. The wave tank is $4.8 \mathrm{~m}$ wide, $24.5 \mathrm{~m}$ long, and has a maximum water depth of 0.60 and $0.40 \mathrm{~m}$, near the piston-type wave generator and in the measuring section, respectively. 
To avoid three-dimensional effects and wave diffraction during the tests with regular waves, a thin dividing wall was used to isolate the measuring section from the rest of the tank. A gently inclined absorbing beach was also constructed to reduce wave reflection by dissipating wave energy.

Wave probes, placed in the section where the horizontal velocity component was measured, recorded simultaneous measurements of the instantaneous water surface elevation. A detailed description of the experimental set-up can be found in Taveira-Pinto [19].

Horizontal velocity component measurements were made using a Laser Doppler Anemometry optical system (Argon-Ion Laser Spectra-Physics Stabilité 2017S operating in single-mode with 2 Watts of power and an optical system consisting of 55X modular LDA optics based on a Dantec fibre optic system and a $60 \mathrm{~mm}$ probe, working in a backscatter configuration). These measurements were taken in different locations, successively nearer to the breakwater and in the seaward and landward slopes, as indicated in Figure 2.

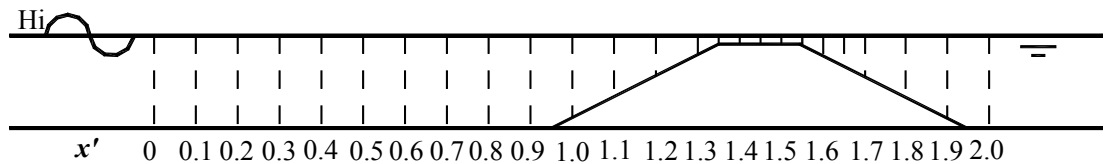

Figure 2: Location of the profiles.

Two models were tested, a rough one and a smooth one, with a crest width of $0.20 \mathrm{~m}$. They had similar dimensions but different roughness qualities. The structure was $0.20 \mathrm{~m}$ height and had $1 \mathrm{~V}: 2 \mathrm{H}$ slopes.

\section{Results and discussion}

The measured regular wave conditions selected for this study were the following: water depth, d, equal to $0.22 \mathrm{~m}$; mean measured wave height, $\overline{\mathrm{H}}_{\mathrm{m}}$, equal to 0.037 $\mathrm{m}$; mean measured wave period, $\overline{\mathrm{T}}_{\mathrm{m}}$, equal to 1.21 ; mean measured wave length, $\overline{\mathrm{L}}_{\mathrm{m}}$, equal to $1.56 \mathrm{~m}$ and mean measured wave celerity, $\overline{\mathrm{C}}_{\mathrm{m}}$, equal to $1.30 \mathrm{~m} / \mathrm{s}$.

The reflection coefficients and the wave phase delay of the smooth and the rough model were calculated, giving a reflection coefficient of 0.114 and 0.068 , and a wave phase delay of $65^{\circ}$ and $18^{\circ}$ respectively, Taveira-Pinto [19].

The evolution of the horizontal velocity and the dynamic pressure along the wave phase were analysed for each measurement point, see Figures 3 to 6 . The measured values were compared with those obtained by the linear wave theory for a reflected wave field. As mentioned before, the dynamic pressure was calculated from the mean measurements and from the theoretical (linear theory) horizontal component of the velocity. The figures represent the measurements of profile at $x^{\prime}=0.5$ and at $x^{\prime}=1.0 \mathrm{~m}$, for the smooth and the rough model. 

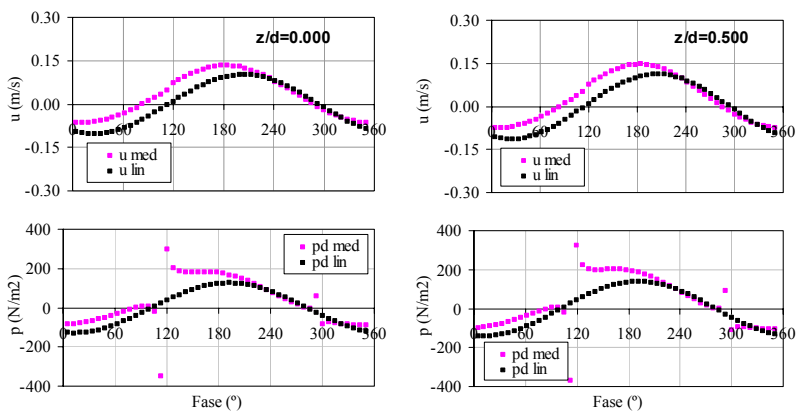

Figure 3: Evolution of horizontal velocity and dynamic pressure along the wave phase (Profile at $x^{\prime}=0.5 \mathrm{~m}$, smooth model).
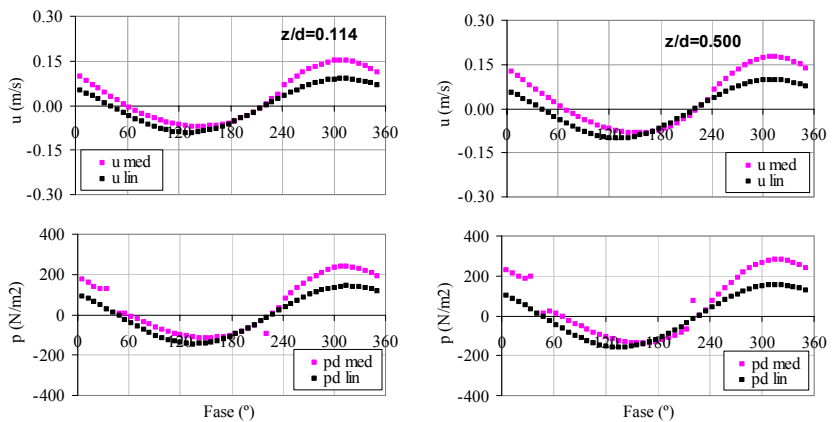

Figure 4: Evolution of horizontal velocity and dynamic pressure along the wave phase (Profile at $x^{\prime}=1.0 \mathrm{~m}$, smooth model).
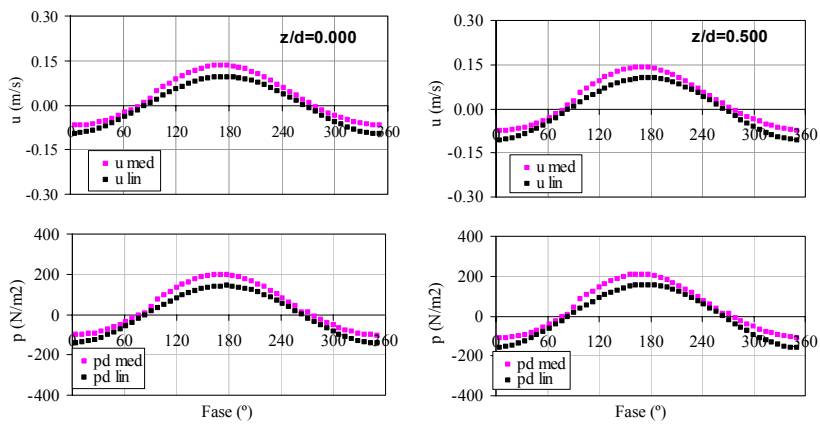

Figure 5: Evolution of horizontal velocity and dynamic pressure along the wave phase (Profile at $x^{\prime}=0.5 \mathrm{~m}$, rough model).

During their propagation, waves deform and begin to shoal when interfering with the rising front of the model (due to the water depth reduction), giving rise to an asymmetric profile and, finally, to an unstable situation where they break (in the crest zone). When this non-linear wave decomposition process starts, the 
use of the linear wave theory is no longer valid. For this reason, we have only used this approach on the seaward side of the structure and in the offshore slope until $x^{\prime}=1.0 \mathrm{~m}$.
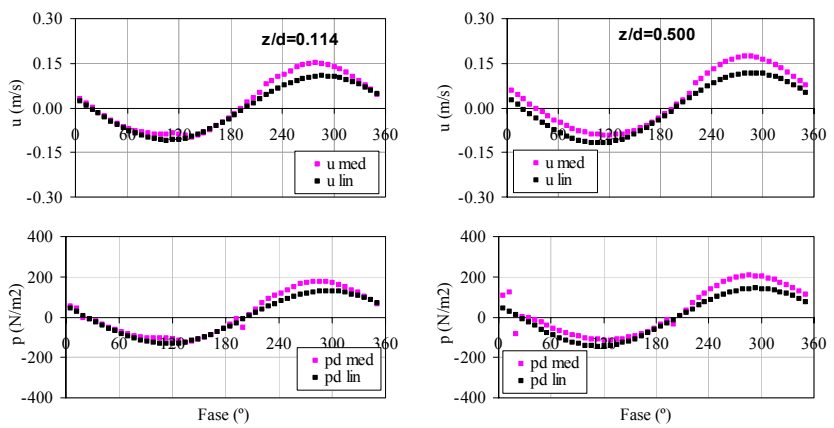

Figure 6: Evolution of horizontal velocity and dynamic pressure along the wave phase (Profile at $x^{\prime}=1.0 \mathrm{~m}$, rough model).

The results of the dynamic pressure for the rough model seem to be in better agreement with the theory than the respective values for the smooth model. This could be explained by the small phase difference verified in the smooth model between the measured velocities and the theoretical ones, which does not occur in the rough model. The dynamic pressure (eqn. 9) depends directly on the value of $\frac{\cos (k x-\sigma t)+C_{r} \cos (k x+\sigma t+\varepsilon)}{\cos (k x-\sigma t)-C_{r} \cos (k x+\sigma t+\varepsilon)}$, which becomes very high when the theoretical horizontal velocity is near zero. If, in this instant, the measured horizontal velocity is not near zero, the dynamic pressure will be very overpredicted.

As expected, the dynamic pressures in the smooth model are higher than in the rough model, as they are not attenuated as much.

\section{Summary and conclusions}

This study demonstrates a methodology to determine the dynamic pressures through the horizontal wave flow velocity component. Although other tests were carried out, only one case for regular waves is presented in order to present the methodology used. Wave-induced dynamic pressure fields for the reflected field were calculated using linear wave theory using the theoretical approach presented, considering that the celerity remained constant until $x^{\prime}=1 \mathrm{~m}$.

For all cases, high velocities and, therefore, high dynamic pressures occurred in the upper measurements, for the higher $\mathrm{z} / \mathrm{d}$ values closer to the water surface. The closer the measurements were to the structure the higher were the velocities and, consequently, the dynamic pressures due to the reduction of the flow section, which led to the increasing velocities.

The calculation of the total horizontal dynamic forces by integration of the pressure field could be useful in determining the more sensitive areas of a 
submerged breakwater, where special care can then be taken in its construction. These conclusions can be particularly important in further investigation on defining critical stability areas. More research, with a wider range of input conditions under regular and irregular sea states closer to prototype conditions, is also being performed.

\section{References}

[1] Allsop, N. W. H., Kortenhaus, A., Oumeraci, H., McConnel, K. J. (2000). New Design Methods for Wave Loadings on Vertical Breakwaters under Pulsating and Impact Conditions. Proceedings of Coastal Structures '99, Inigo Losada, Balkema, Santander, Spain, Vol. II, pp. 595-602.

[2] Browder, A. E., Dean, R. G., Chen, R. (1996). Performance of a Submerged Breakwater for Shore Protection, Proceedings of the $25^{\text {th }}$ International Conference Coastal Engineering 1996, ASCE, Orlando, Florida,USA, Vol. II, pp. 2312-2323.

[3] Bullock G. N., Hewson P. J., Crawford A. R., Bird, P. A. D. (2000). Field and Laboratory Measurements of Wave Loads on Vertical Breakwaters. Proceedings of Coastal Structures '99, Inigo Losada, Balkema, Santander, Spain, Vol. II, pp. 613-621.

[4] Burcharth, H. F. (1994). The Design of Breakwaters. Coastal, Estuarial and Harbour Engineers' Reference Book, M. B. Abbott e W. A. Price, E \& FN SPON, London, UK, pp. 381-424.

[5] Chen, B. F., Chen, P. H. (2001). Fully Nonlinear Waves Past Submerged and Floating Breakwater, Proceedings of the XXIX IAHR Congress, Beijing, China.

[6] Dean, R. G, Dalrymple, R. A. (1991). Water Wave Mechanics for Engineers and Scientists, World Scientific, Advanced Series on Ocean Engineering, Vol. II, pp. 78-90.

[7] Demirbilek, Z., Vincent L. (2002). Water Wave Mechanics. Coastal Engineering Manual Outline, S. Army Corps of Engineers, Washington, DC, chapter II-1, pp. 1-35.

[8] Fuhrboter, I. A. (1994). Wave Loads on Sea Dikes and Sea-Walls. Coastal, Estuarial and Harbour Engineers' Reference Book, M. B. Abbott e W. A. Price, E \& FN SPON, London, UK, pp. 351-367.

[9] Gironella, X., Sánchez-Arcilla, A. (2000). Hydrodynamic Behaviour of Submerged Breakwaters. Some Remarks Based on Experimental Results. Proceedings of Coastal Structures '99, Inigo Losada, Balkema, Santander, Spain, pp. 891-896.

[10] Groenewoud, M., vand de Graaff, J., Claessen, E., van der Biezen, S. (1996). Effect of Submerged Breakwater on Profile Development. Proceedings of the $25^{\text {th }}$ International Conference Coastal Engineering 1996, ASCE, Orlando, Florida,USA, Vol. II, pp. 2428-2441.

[11] Hsu, T. W., Ou, S. H., Hou, H. S., Shin, C. Y. (2001). Wave-induced Vortices Around a Submerged Breakwater by FLDV and PIV. 
Proceedings of the International Conference Coastal Engineering 2000, ASCE, Orlando, Florida, USA, Vol. 2, pp. 2278-2291.

[12] Lamberti, A., Mancinelli, A. (1996). Italian Experience on Submerged Barriers as Beach Defence Structures. Proceedings of the $25^{\text {th }}$ International Conference Coastal Engineering 1996, ASCE, Orlando, Florida,USA, Vol. II, pp. 2352-2365.

[13] Lara, J. (2005). A Numerical Wave Flume to Study the Functionality and Stability of Coastal Strucutres. PIANC Magazine AIPCN, International Navigation Association, $n^{\circ} 121$ October, pp. 5-29, ISSN 0374-1002.

[14] Luís, L. (2001). Pressure in Vertical and Inclined Walls due to Wave Breaking. (in Portuguese). MSc Thesis, Instituto Superior Técnico, Portugal.

[15] Martin, F. L., Losada, M. A., Vidal, C., Diaz Rato, J. L. (1996). Prototype Measurements of Wave Pressures on a Wave Screen: Comparison to Physical and Analytical Models. Proceedings of the $25^{\text {th }}$ Int. Conference Coastal Engineering, ASCE, Orlando, Florida, USA, Vol. II, pp. 17631775.

[16] Saitoh, T., Ishida, H. (2001). Kinematics and Transformation of New Type Wave Front Breaker Over Submerged Breakwater, Proceedings of the 4th International Symposium Waves 200: Ocean Wave Measurement and Analysis, ASCE, California, USA, Vol. II, pp. 1032-1041.

[17] Taveira-Pinto, F., Proença, M. F., Veloso Gomes, F. (2000). Experimental Analysis of the Behaviour of Submerged Breakwaters (in Portuguese). Comunicação das $1^{\text {as }}$ Jornadas Portuguesas de Engenharia Costeira $e$ Portuária 1999, AIPCN/PIANC, Porto, Portugal, pp. 71-90.

[18] Taveira-Pinto, F., Proença, M. F., Veloso-Gomes, F. (2001). Spatial Regular Wave Velocity Field Measurements Near Submerged Breakwaters. Proceedings of the 4th International Symposium Waves 2001, San Francisco, USA, ASCE, Vol. II, pp. 1136-1149, ISBN 0-78440604-9.

[19] Taveira-Pinto, F. (2002). Oscillations and Velocity Field Analysis Near Submerged Breakwaters Under the Wave Action (in Portuguese). PhD Thesis, Faculty of Engineering of University of Porto, Porto, Portugal.

[20] Taveira-Pinto, F., Neves, A. C. (2003). Second-Order Analysis of Dynamic Pressure Profiles, using Measured Horizontal Wave Flow Velocity Component. Proceedings of the $6^{\text {th }}$ International Conference on Coastal Engineering 2003, Cadiz, Spain.

[21] Taveira-Pinto, F., Neves, A. C. (2003). Environmental Aspects of Using Detached for Coastal Protection Purposes. Proceedings of the International Symposium ENVIRONMENT 2010: Situation and Perspectives for the European Union, Porto, Portugal, paper G14, ISBN 972-98944-0-x.

[22] Tomasicchio, U. (1996). Submerged Breakwaters for the Defence of the Shoreline of Ostia - Field experiences, comparison. Proceedings of the $25^{\text {th }}$ International Conference Coastal Engineering 1996, ASCE, Orlando, Florida,USA, Vol. II, pp. 2404-2417. 